\title{
MODELING OF STUDENT'S ACADEMIC PERFORMANCE AND PROGRESSION IN INDIAN PRIVATE UNIVERSITIES USING MARKOV CHAIN
}

\author{
${ }^{1}$ Yakubu I.Kibiya, ${ }^{2}$ Shamsuddeen A. Sabo, \\ ${ }^{3}$ Ibrahim Z. Musa and ${ }^{4} \mathrm{~J}$. M. Ibrahim \\ ${ }^{1,2,3,4}$ Department of Mathematics, Mewar University, India.
}

\begin{abstract}
Knowing the pattern of student academic performance and their progression across various levels during their study period will enable the University to make prediction based on which proper learning can be achieved. This research work employ Markov chain approach to study the pattern of student's movement across various study levels at department of Business Administration Mewar University. In this research work, a model for estimation was developed based on the stochastic nature of the data, a finite Markov chain with three transient and two absorbing states was developed. It was discovered that the probability of graduation increases, while the rate of withdrawal decreases as the student progress to the highest level. It was also established that, a student at Mewar University is expected to spend 1.0270 academic year for the first year, 0.9411 academic year for the second year and 0.9060 academic year for the third year.
\end{abstract}

Keywords: Markov Chain, Academic Performance, Transition and Transient State, Fundamental Matrix, Absorption state.

\section{INTRODUCTION}

Learning as a continuous process is designed in such a way that students are assessed based on some specified criteria for their academic progress. To achieve this, educational institutions across the world developed a grading system as a tool to measure the abilities or otherwise of students to cross from one educational level to another [1]. In universities, in particular, students are assessed based on their Grade Point Average(GPA) or Cumulative Grade Point Average(CGPA) scale.Alsoat the termination of their study, such criteria are used to award a class of degree based on their CGPA. Modeling the student academic performance is a problem which when solved will help educational institutions in knowing the flow pattern of their students so as to plan for the futureadmissions and other necessities [2].

The theory of probability was designed to handle non-deterministic phenomena. Academic performance as non-deterministic phenomena that changes over time can be modeled using a stochastic process. A stochastic or random process is a mathematical object defined as a collection of random variables indexed by time as a parameter [3]. A Markov process is a stochastic process indexed by time with the property that the future state depends only on the present state of the process, it has zero memory of the past. That is given the current state of the process $X_{t}$ at time $t$, the future $X_{t+k}$ is independent of $X_{u}$ for $U<t$.A Markov chain is a discrete Stochastic process describing a sequence of possible events in which the probability of each event depend only on the state attained in the previous event [4], [5], [6], [7], [8] and [9].The present research intends to modelled the students' academic performance and progression in Indian private universities using Mewar University as a case study. Statistical R-programming Software was used to analyze the data. 
So many researches are available on this topic and are as important as they are, because of the widespread application of Markov chain in studying the pattern of the student movement in higher institutions. [10] Used Markov chain approach to demonstrate the authenticity of grading questions in an adaptive assessment.[2] Used Markov approach to demonstrate that, the rate of withdrawal decreases as the student progress to the highest level of learning in universities.[11] Used Markov approach to model student flow in private tertiary institutions in Nigeria.[12] Used Markov approach to predict Secondary school enrolment and project teachers recruitment.[13] Apply Markov chain in estimating the mean life time of students in different levels of study. [14] Use the Markov chain to develop a model to study the flow of undergraduate through higher education in Solevania. [15] Used the Markov chain approach in modelling enrolment projection in Mwenge University.

\section{METHODOLOGY}

We use the theory of absorbing Markov chain as a model to analyze the academic performance and progression. An absorbing Markov chain with $r$ absorbing and $t$ transient states have the following canonical general form;

$$
P=\left[\begin{array}{lll}
{\left[\begin{array}{ccc}
Q_{11} & \cdots & Q_{1 t} \\
\vdots & \ddots & \vdots \\
Q_{t 1} & \cdots & Q_{t t}
\end{array}\right]} & {\left[\begin{array}{lll}
R_{11} & \cdots & R_{1 r} \\
\vdots & \ddots & \vdots \\
R_{t 1} & \cdots & R_{t r}
\end{array}\right]} \\
{\left[\begin{array}{lll}
O_{11} & \cdots & O_{1 t} \\
\vdots & \ddots & \vdots \\
O_{r 1} & \cdots & O_{r t}
\end{array}\right]} & {\left[\begin{array}{lll}
I_{11} & \cdots & I_{r 1} \\
\vdots & \ddots & \vdots \\
I_{r 1} & \cdots & I_{r r}
\end{array}\right]}
\end{array}\right] \text { (1) }
$$

Where

$Q=t \times t$ matrix that show transition between transient states with $Q_{i j}$ elements for $i=j=1,2,3, \ldots, t$

$R=t \times r$ transition matrix from the transient state to the absorbing state with $R_{i j}$ elements for $i=j=1,2,3, \ldots, t$

$O=r \times t$ zero matrix with $O_{i j}$ elements for $i=1,2,3, \ldots, r$ and $j=1,2,3, \ldots, t$

$I=r \times r$ identity matrix with $I_{i j}$ elements for $i=1,2,3, \ldots, r$ and $j=1,2,3, \ldots, r$

The transition matrix is said to be in canonical form.

\section{A. FUNDAMENTAL MATRIX}

Given an absorbing Markov chain $P$, the fundamental matrix for $P$ is given as $M=(I-Q)^{-1}$ The entries $n_{i j}$ of the matrix $M$ gives the expected number of time the process is in the transient state $j$ if it started in the transient state $i$

$$
M=(I-Q)^{-1}
$$

Where $I$ is an identity matrix of size $t \times t$, contrary to its original size in (1) which is $r \times r$. 


\section{B. TIME OF ABSORPTION}

Let $\mu_{i}$ be the mean number of steps before the Markov chain is absorbed into one of its absorbing states when it stated in the transient state $i$ and let $\mu$ be the column vector whose $i^{\text {th }}$ entry is $\mu_{i}$ then; $\mu=\mathrm{M} C(3)$

With $M$ the fundamental matrix and $C$ is a column vector all of whose entries are 1's.

\section{ABSORPTION PROBABILTY}

Let $b_{i j}$ be the probability that an absorbing Markov chain will be absorbed in the absorbing state $j$ if it starts in the transient state $i$. Let $B$ be the matrix with entries $b_{i j}$, then $B$ is a $t \times t$ Matrix calculated as;

$B=M R(4)$

Where

$M \rightarrow$ Fundamental matrix.

$R \rightarrow$ Sub matrix obtained from the transitionsmatrix

\section{MODEL}

To complete bachelor degree in the department of business administration at Mewar university, a student had to spent at least three years. Hence, as a means of modeling the students' academic progress we define the following states;

- 1 Level $\rightarrow$ The student registered in the first year of the study program.

- 2 Level $\rightarrow$ The student is registered in the second year of the study program.

- $\quad 3$ Level $\rightarrow$ The student is registered in the final year of the study program.

- $W \rightarrow$ Student has been withdrawn from the study program.

- $G \rightarrow$ Student graduated and completed the program effectively.

\section{ASSUMPTIONS}

1. A student who is currently in the first or second year can either progressto the next stage of learning or repeat the current year i.e. stay in the same stage.

2. A student who is currently in the third year can either graduate i.e. finish the program or repeat the current year.

3. Student who has been withdrawn will never finish the program.

4. Student who successfully gradated and finish the study program will not apply for the same program again.

The probability transition matrix describing the progress of student from the first study year to the towards graduation is; 


$$
P=\left[\begin{array}{llllll} 
& 1 L & 2 L & 3 L & W & G \\
1 L & P_{11} & P_{12} & 0 & P_{1 W} & 0 \\
2 L & 0 & P_{22} & P_{23} & P_{2 W} & 0 \\
3 L & 0 & 0 & P_{33} & P_{3 W} & P_{3 G} \\
W & 0 & 0 & 0 & 1 & 0 \\
G & 0 & 0 & 0 & 0 & 1
\end{array}\right]
$$

\section{RESULTS AND DISCUSSION}

The enrolment and performances of the student over a period of ten academic years is summarize in the table below;

\begin{tabular}{|c|c|c|c|}
\hline & $1^{\text {st }}$ Year & $2^{\text {nd }}$ Year & $3^{\text {rd }}$ Year \\
\hline$P$ & \begin{tabular}{|l|l}
175 \\
\end{tabular} & 181 & 0 \\
\hline $\mathrm{R}$ & 5 & 3 & 8 \\
\hline $\mathrm{W}$ & 10 & 13 & 3 \\
\hline G & 0 & 0 & 0 \\
\hline TOTAL & 190 & 194 & 196 \\
\hline & $\begin{array}{l}\text { Promote } \\
=100 \mathrm{Le}\end{array}$ & $\begin{array}{l}=\text { Repea } \\
L=200\end{array}$ & $\begin{array}{l}W=w \\
3 L=3\end{array}$ \\
\hline
\end{tabular}

\section{ESTIMATION OF THE PROBABILITY TRANSITION MATRIX}

From the table above we can develop our one step probability transition matrix as follows;

$$
N_{i j}=\left[\begin{array}{llllll} 
& 1 L & 2 L & 3 L & W & G \\
1 L & 5 & 175 & 0 & 10 & 0 \\
2 L & 0 & 3 & 181 & 13 & 0 \\
3 L & 0 & 0 & 8 & 3 & 0 \\
W & 0 & 0 & 0 & 26 & 0 \\
G & 0 & 0 & 0 & 0 & 185
\end{array}\right]
$$

Dividing the frequencies in each row by its corresponding row total, we obtain the transition probability matrix in canonical form. The probability of student remaining in an academic state and the probability of he/she moving to the next academic state is revealed by this canonical matrix.

$$
P_{i j}=\left(\begin{array}{lllll}
0.0263 & 0.9021 & 0.0000 & 0.3286 & 0.0000 \\
0.0000 & 0.0155 & 0.9235 & 0.5000 & 0.0000 \\
0.0000 & 0.0000 & 0.0408 & 0.1154 & 0.0000 \\
0.0000 & 0.0000 & 0.0000 & 1.0000 & 0.0000 \\
0.0000 & 0.0000 & 0.0000 & 0.0000 & 1.0000
\end{array}\right)
$$

We can decompose the one step probability matrix $P_{i j}$ into the transient state $\left(Q_{i j}\right)$, absorbing state $\left(R_{i j}\right)$, an identity matrix $\left(I_{i j}\right)$ and the zero matrix $\left(O_{i j}\right)$ respectively as follows; 


$$
\begin{aligned}
Q_{i j} & =\left[\begin{array}{lll}
0.0263 & 0.9021 & 0.0000 \\
0.0000 & 0.0155 & 0.9253 \\
0.0000 & 0.0000 & 0.0408
\end{array}\right] \\
R_{i j} & =\left[\begin{array}{cc}
W & G \\
0.3846 & 0.0000 \\
0.5000 & 0.0000 \\
0.1154 & 0.9439
\end{array}\right] \\
O_{i j}= & {\left[\begin{array}{lll}
0.0000 & 0.0000 & 0.0000 \\
0.0000 & 0.0000 & 0.0000
\end{array}\right] } \\
I_{i j}= & \left(\begin{array}{ll}
1 & 0 \\
0 & 1
\end{array}\right) \\
M= & {\left[\begin{array}{lll}
I-M & -1
\end{array}=\left[\begin{array}{lll}
1.0000 & 0.0000 & 0.0000 \\
0.0000 & 1.0000 & 0.0000 \\
0.0000 & 0.0000 & 1.0000
\end{array}\right]-\left[\begin{array}{lll}
0.0263 & 0.9021 & 0.0000 \\
0.0000 & 0.0155 & 0.9253 \\
0.0000 & 0.0000 & 0.0408
\end{array}\right]\right]^{-1} } \\
& =\left[\begin{array}{lll}
1.0270 & 0.9411 & 0.9060 \\
0.0000 & 1.0157 & 0.9779 \\
0.0000 & 0.0000 & 1.0425
\end{array}\right]
\end{aligned}
$$

Looking at the matrix above, one can clearly see that, a student in the university is expected to spend 1.0270 academic year in the first year of the study program, 0.9411 in the second year and 0.9060 for the third year during his/her enrolment in the study program.

\section{EXPECTED TIME UNTIL ABSORPTION (Withdrawal or Graduation)}

$$
\begin{aligned}
& \mu=\left[\begin{array}{lll}
1.0270 & 0.9411 & 0.9060 \\
0.0000 & 1.0157 & 0.9779 \\
0.0000 & 0.0000 & 1.0425
\end{array}\right]\left[\begin{array}{l}
1 \\
1 \\
1
\end{array}\right] \\
& \mu=\left[\begin{array}{l}
2.8741 \\
2.0836 \\
1.0425
\end{array}\right]
\end{aligned}
$$

The column vector above shows the expected time until absorption (Withdrawal or Graduation) from a given transient state.

\section{PROBABILITY OF ABSORPTION (Withdrawal or Graduation)}

The probability that the process will enter $j^{\text {th }}$ absorbing state if it starts in the $i^{\text {th }}$ transient state is called the probability of absorption and its given as $B=M R$ 


$$
B=\left[\begin{array}{cc}
W & G \\
0.9701 & 0.0299 \\
0.6207 & 0.3793 \\
0.1203 & 0.8797
\end{array}\right]
$$

Looking at the matrix $B$ above one can clearly see that the probability of graduation increases as the student progress over the study stages and also the probability of withdrawal decreases.

$$
\text { for } n=2
$$

$\left[\begin{array}{ccc}{[1]} & {[2]} & {[3]} \\ 0.00069169 & 0.03770778 & 0.83308935 \\ 0.00000000 & 0.00024025 & 0.05199305 \\ 0.00000000 & 0.00000000 & 0.00166464\end{array}\right]$

For $n=3$

$\left[\begin{array}{ccc}1.819145 e-05 & 1.208444 e-03 & 6.881318 e-02 \\ 0.000000 e+00 & 3.723875 e-06 & 2.343187 e-03 \\ 0.000000 e+00 & 0.000000 e+00 & 6.791731 e-05\end{array}\right]$

For $n=4$

$$
\left[\begin{array}{ccc}
4.784351 e-07 & 3.514139 e-05 & 3.923576 e-03 \\
0.000000 e+00 & 5.772006 e-08 & 9.904104 e-05 \\
0.000000 e+00 & 0.000000 e+00 & 2.771026 e-06
\end{array}\right]
$$

For $n=5$

$$
\left[\begin{array}{ccc}
1.258284 e-08 & 9.762878 e-07 & 1.925350 e-04 \\
0.000000 e+00 & 8.946610 e-10 & 4.094179 e-06 \\
0.000000 e+00 & 0.000000 e+00 & 1.130579 e-07
\end{array}\right]
$$

\section{DISCUSSION OF RESULTS}

Looking at the transition probability, it is clear that the probability of graduation increases as the student progress to the highest level. While the rate of withdrawal decreases. This shows an improvement in the performance of the student as the they move from lower to the highest level. It was also established that, a student at Mewar university is expected to spend 1.0270 academic year for the first year, 0.9411 academic year for the second year and 0.9060 academic year for the third year.

\section{CONCLUSION}

In this research, Markov chain model was developed to study the academic performance and progression flow of the student of Mewar University, India using a data of the student from the departmentof management studies. The transition data was used to examine the pattern of the undergraduate student flow from one level to another in the department. The model gives 
the expected number of student that graduated, average time a student will stay to complete the study program.

\section{REFERENCES}

[1] Oluwunmi, A. O., Ajibola, M. O.,Iroham, C. O. \& Eluyele, P. (2017) 'Students' Satisfaction with Major Academic Facilities inPrivate Universities in Ogun State, Nigeria"Covenant Journal of Business \& Social Sciences (CJBSS) Vol. 8 No.1, June, 2017.

[2] Brezavšček, A., Bach, M. P., \& Baggia, A. (2017). Markov Analysis of Students' Performance and Academic Progress in Higher Education. Organizacija, 50(2), 83-95. https://doi.org/10.1515/orga-2017-0006

[3] Himansu Chaurasiya and K.M Soni. Probability, Random variables and Stochastic Methods. Pp: 150-175

[4] Buccellato, S. M., \& Tornatore, E. (2008). Multi-phase epidemic model by a Markov chain. 387, 3555-3562. https://doi.org/10.1016/j.physa.2008.01.115

[5] Kazemi, A., Modarres, M., Mehregan, M. R., Neshat, N., \& Foroughi, A. A. (2011). A Markov Chain Grey Forecasting Model : A Case Study of Energy Demand of Industry Sector in Iran. 12, 13-18.

[6] Khajehghiasi, M. K., \& Alinezhad, A. (2019). Forecast of Climatologically Events Using Improved Grey Model ( Case Study: Qazvin Province Climatology ). 11(1), 49-56.

[7] Kim, M., Paini, D., \& Jurdak, R. (2019). Modeling stochastic processes in disease spread across a heterogeneous social system Regional outbreaks. 116(2). https://doi.org/10.1073/pnas.1801429116

[8] Lan, J., \& Zhou, Y. (2014). Application of Gray Markov SCGM ( 1, 1 ) c Model to Prediction of Accidents Deaths in Coal Mining. 2014.

[9] Tonini, F., Hochmair, H. H., Scheffrahn, R. H., \& Deangelis, D. L. (2014). Ecological Informatics Stochastic spread models: A comparison between an individual-based and a lattice-based model for assessing the expansion of invasive termites over a landscape. Ecological Informatics, 24, 222-230. https://doi.org/10.1016/j.ecoinf.2014.09.011

[10] Geetha, V., Nandakumar G. S., \& Vivek R. (2018). Application of Markov Chain for Comparing the Performance of Students in Adaptive E-Assessment. 118(18), 27972803.

[11] Amiens, E. O., \& Oisamoje, M. D. (2016). Students Flow in Private Universities in Nigeria: A Markov Chain Modelling Approach. European Journal of Business and Management, 8(8), 107-114.

[12] Egbo, M. N., Bartholomew, D. C., Okeke, J. U., \& Okeke, E. N. (2018). Markov Chain Approach to Projection of Secondary School Enrolment and Projection of Teachers. Open Journal of Statistics, 08(03), 533-555. https://doi.org/10.4236/ojs.2018.83035

[13] Muhammad, M. A., Falgore, J. Y., \& Sani, U. H. (2019). Analysis of Students' Academic Performance and Progression (Using Markov Chain Approach). International Journal of Engineering Applied Sciences and Technology, 04(07), 187193. https://doi.org/10.33564/ijeast.2019.v04i07.031

[14] Alawadhi, S., \& Konsowa, M. (2010). Markov chain analysis and student academic progress: An empirical comparative study. Journal of Modern Applied Statistical Methods, 9(2), 584-595. https://doi.org/10.22237/jmasm/1288585500

[15] Bairagi, A., \& Kakaty, S. C. (2017). A Stochastic process Approach to Analyse Students ' Performance in Higher Education Institutions. 12(2), 323-342. 